\title{
Modeling of Radon and Its Short-Lived Decay Products during Showering: Dose to Adult Members of the Public
}

\author{
Rabi Rabi ${ }^{1 *}$, Lhoucine Oufni1 ${ }^{1}$, Khamiss Cheikh${ }^{2}$, El-Houcine Youssoufi' ${ }^{1}$, Hamza Badry ${ }^{1}$, \\ Youssef Errami ${ }^{2}$
}

${ }^{1}$ Department of Physics (LPM), Sultan Moulay Sliman University, Beni-Mellal, Morocco

${ }^{2}$ Department of Physics (LPM), Chouaib Doukkali University, El Jadida, Morocco

Email: ^rabiismcm@gmail.com

How to cite this paper: Rabi, R., Oufni, L., Cheikh, K., Youssoufi, E.-H., Badry, H. and Errami, Y. (2021) Modeling of Radon and Its Short-Lived Decay Products during Showering: Dose to Adult Members of the Public. World Journal of Nuclear Science and Technology, 11, 84-99.

https://doi.org/10.4236/wjnst.2021.112006

Received: January 23, 2021

Accepted: March 30, 2021

Published: April 2, 2021

Copyright $\odot 2021$ by author(s) and Scientific Research Publishing Inc. This work is licensed under the Creative Commons Attribution International License (CC BY 4.0).

http://creativecommons.org/licenses/by/4.0/

\begin{abstract}
Human exposure to radon inside different parts of the house has become a great concern. In this study, the distribution of radon and its decay inside the shower will be numerically investigated. In fact, the radon concentration in water is measured through the use of AlphaGUARD. They are used as an input for CFD simulation. The numerical results proved that temperature and humidity have significant impacts on both radon content and distribution. Also, the equilibrium factor variations between radon and its progeny with the temperature and relative humidity were carefully looked at. The equivalent doses due to ${ }^{218} \mathrm{Po}$ and ${ }^{214} \mathrm{Po}$ were evaluated in different tissues of the respiratory tract of the members of the public from the inhalation of air inside the shower. The annual effective dose due to radon short lived decay from the inhalation of air inside the shower by the members of the public was also investigated.
\end{abstract}

\section{Keywords}

Radon, Temperature, Shower, Computational Fluid Dynamics (CFD), Effective Dose

\section{Introduction}

Radon $\left({ }^{222} \mathrm{Rn}\right)$, being naturally occurring radioactive, noble gas with a half-life of 3.82 days, is one such important potential health hazard concerning radiation hygiene in modern days. It originates from the radioactive decay of naturally occurring uranium [1] and radium deposits, which is picked up by groundwater passing through rocks and soil containing such radioactive substances and then 
enters water supplies, when this water is pumped up a well [2].

The concentration of radon is generally low in the surface water as compared to the underground water because of the presence of granite, sand and gravels [3] [4] [5]. The water soluble radon is an important secondary source for the indoor radon exposure. This soluble radon, degas from the usable water inside the dwellings and becomes airborne [6]. Therefore the indoor radon concentration increases simultaneously with the high radon content in the water. Due to the presence of radon in water, the inhalation and ingestion cause exposure to the lungs and stomach respectively, out of which inhalation is expected to cause much health risk [7].

Computational fluid dynamics (CFD) has been used as a powerful tool in various contexts in different research areas such as aerosol science and technology [8] [9], chemical industries [10] [11] [12]. In recent time, computational fluid dynamics (CFD) has been used for simulating ${ }^{222} \mathrm{Rn}$ and ${ }^{220} \mathrm{Rn}$ characteristics in indoor environments [13] [14] [15] [16]. CFD simulations are being projected as a powerful tool for supplementing ${ }^{222} \mathrm{Rn}$ and ${ }^{220} \mathrm{Rn}$ research in the indoor air [17] [18] [19] [20]. The applicability of CFD for radon related research is still evolving and a lot needs to be done in applying this knowledge for mankind research.

In the current study, a numerical model was applied to investigate radon distribution and its decay in a typical shower. The influence of water temperature, relative humidity on radon distribution and its decay in the shower was analysed. We also determined the annual equivalent doses obtained from inhalation of radon, resulting from the water used in a shower, in various compartments of the human body of adults from the general population.

\section{The Numerical Method}

\subsection{Physical Model}

The shower and manikin were modelled with a CFD (Computational Fluid Dynamics) software package for predicting the behavior of radon in the shower. The CFD model of the shower and the position of manikin in the shower are shown in Figure 1. The size of the shower is $(1 \mathrm{~m} \times 1 \mathrm{~m} \times 2 \mathrm{~m})$, as well as the manikin had the standard height $(1.70 \mathrm{~m})$, and the total surface area $\left(1.81 \mathrm{~m}^{2}\right)$. A bank of shower heads was located in the center of the chamber, normally at a height of $1.60 \mathrm{~m}$ from the floor, and the diameter of the orifice in the shower head is of the order $4 \mathrm{~mm}$.

\subsection{The Numerical Approach}

In the model, ${ }^{222} \mathrm{Rn}$ was assumed to be emitted from the water of the shower. Once it enters the shower; it mixes with air and disperses in three dimensions. The air flow inside the room was considered as continuous and incompressible in laminar regime. The unsteady-state flow field was established inside the shower using equations of continuity and momentum conservation (Equations (1)-(3)) [20]: 


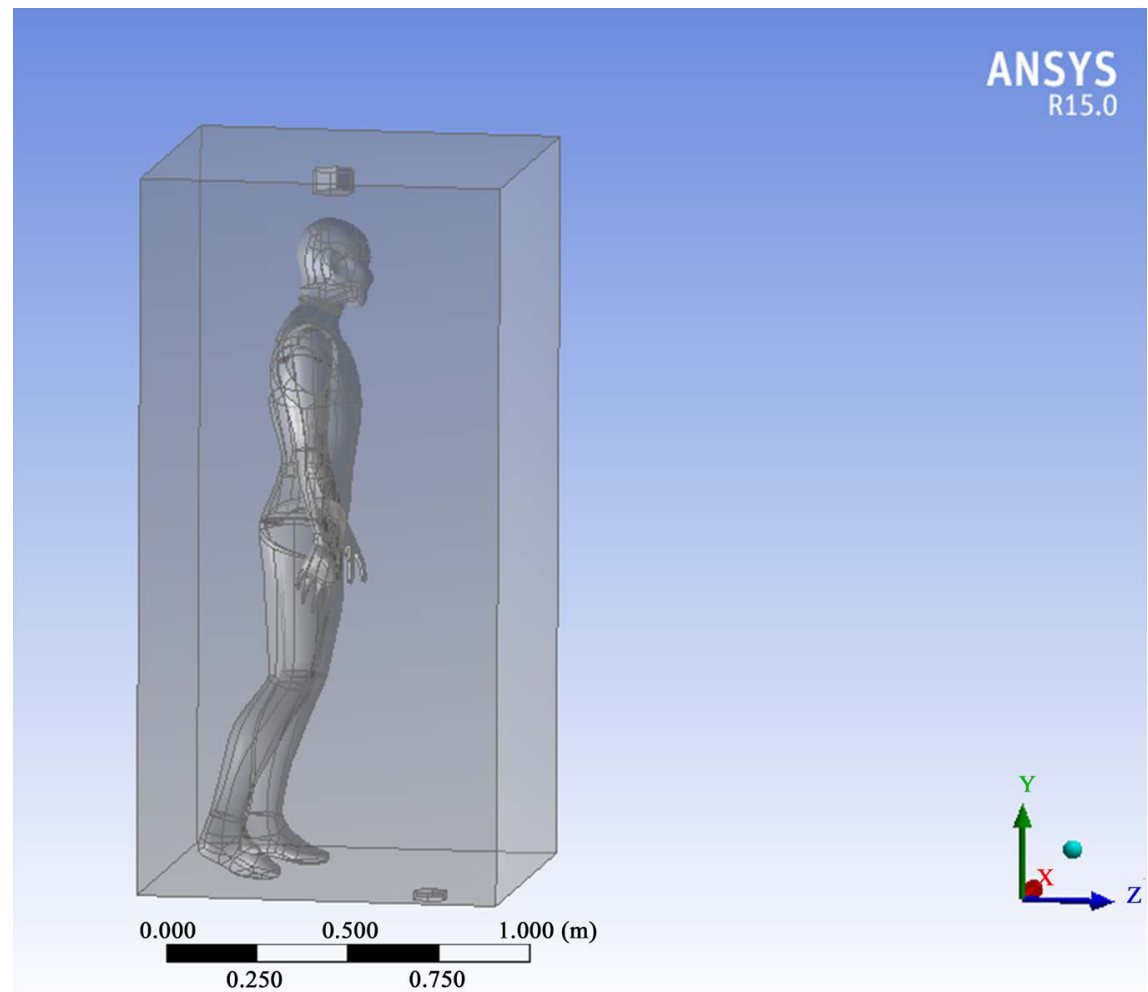

Figure 1. Geometrical of the shower model and position of the manikin.

$$
\begin{gathered}
\frac{\partial\left(\rho U_{i}\right)}{\partial X_{i}}=0 \\
\frac{\partial\left(\rho U_{i}\right)}{\partial t}+\frac{\partial\left(\rho U_{i} U_{j}\right)}{\partial X_{i}}=-\frac{\partial P}{\partial X_{i}}+\frac{\partial}{\partial X_{i}}\left[\mu\left(\frac{\partial U_{i}}{\partial X_{i}}+\frac{\partial U_{j}}{\partial X_{i}}\right)\right]+\rho g \\
\frac{\partial T}{\partial t}+\frac{\partial\left(U_{i} T\right)}{\partial X_{i}}=\alpha \frac{\partial^{2} T}{\partial X_{i}^{2}}
\end{gathered}
$$

where, $X$ is the coordinate axis in the direction $(i=1,2,3), U_{i}$ corresponds to the mean velocity $\left(\mathrm{m} \cdot \mathrm{s}^{-1}\right)$ in the $i$ direction, and $\rho$ is mixture density (Air- ${ }^{222} \mathrm{Rn}$ ) $\left(\mathrm{Kg} \cdot \mathrm{m}^{-3}\right)$. Here $P$ is pressure $\left(\mathrm{N} \cdot \mathrm{m}^{-2}\right), \mu$ is the molecular viscosity $\left(\mathrm{N} \mathrm{s} \cdot \mathrm{m}^{-2}\right), \alpha$ thermal diffusivity $\left(\mathrm{m}^{2} \cdot \mathrm{s}^{-1}\right)$ and $g$ is the gravitational acceleration $\left(\mathrm{m}^{2} \cdot \mathrm{s}^{-1}\right)$.

The dispersion of radon and its decay were simulated by Equation (4):

$$
\frac{\partial C_{j}}{\partial t}+\frac{\partial\left(U_{i} C_{j}\right)}{\partial X_{i}}=D_{j} \frac{\partial^{2} C_{j}}{\partial X_{i}^{2}}-\left(\lambda_{j}+\lambda_{d}\right) C_{j}
$$

where, $C_{j}$ is the concentrations of $f^{\text {th }}$ radon decay in the shower $\left(\mathrm{Bq} \mathrm{m}^{-3}\right)$, respectively $\left(j=0,1,2,3\right.$ and 4 for ${ }^{222} \mathrm{Rn},{ }^{218} \mathrm{Po},{ }^{214} \mathrm{~Pb},{ }^{214} \mathrm{Bi}$ and ${ }^{214} \mathrm{Po}$ ), $D$ is the coefficient of Brownian diffusivity $\left(\mathrm{m}^{2} \cdot \mathrm{s}^{-1}\right), U$ are air flow velocity's, $\lambda_{j}$ is the radioactive decay constant $\left(\mathrm{h}^{-1}\right)$ and $\lambda_{d}$ is a deposition rate of the radon decay products.

\subsection{Numerical Solution and Boundary Conditions}

In this paper, CFD modelling was conducted with the Fluent code which is 
based on Finite Volume Method to simulate the radon distribution inside the shower. The pressure-velocity coupling was accomplished through an iterative solution method, SIMPLE algorithm. Second-order upwind schemes were used to solve the basic governing equations of the discrete such as momentum, while the standard equation was used for the pressure term. The radon dispersion equation was then coupled with the indoor airflow in order to obtain the dispersion of radon.

The hexahedral grids with an interval size of $0.0005 \mathrm{~m}$ were used (Figure 2). A sensitivity analysis of the numerical scheme on the grid refinement was also performed by using a finer grid size of $0.00025 \mathrm{~m}$. However, changes to the results were trivial. To confirm numerical convergence on the model, the equation residuals were prevented from changing drastically through iterations, with residuals of conservation equations for ${ }^{222} \mathrm{Rn}$ set to less than $10^{-5}$.

The boundary conditions for the surfaces of the shower and the manikin as well as to the inlet and outlet openings are listed in Table 1. In this modelling, inlet boundary condition is taken as a source of radon in the shower. Therefore, an experiment was carried out to measure the radon concentration level in the

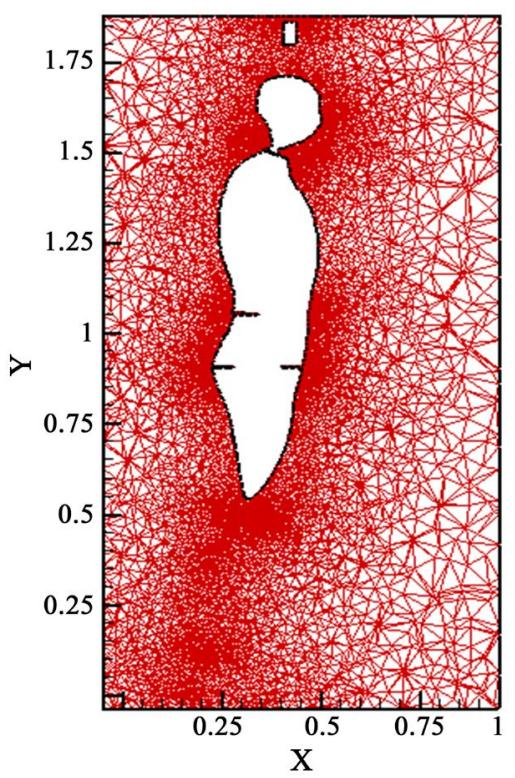

Figure 2. The mesh structure of the shower.

Table 1. Boundary conditions.

\begin{tabular}{cc}
\hline Location & Boundary condition \\
\hline Inflow boundary & $U=W=0 ; V=V_{\text {inlet }} ; T=T_{\text {inlet }} ; \quad C=C_{\text {inlet }}$ \\
Outflow boundary & $\frac{\partial(U, V, W, T, C)}{\partial Y}=0$ \\
Walls & $U=V=W=C=0, \quad \frac{\partial T}{\partial X}=\frac{\partial T}{\partial Y}=\frac{\partial T}{\partial Z}=0$ \\
Surface manikin & $U=V=W=C=0, T=306 \mathrm{~K}$
\end{tabular}


tap water using AlphaGUARD technique [21].

The wall boundary condition of radon decay is simplified as zero normal gradients. That is $\frac{\partial C_{j}}{\partial n}=0$, where $n$ is the direction normal to the wall [20].

\subsection{Numerical Solution and Boundary Conditions}

Radon levels in water were determined by using AlphaGUARD technique. All water samples were carefully collected to prevent escape of the radon gas from samples. Water was allowed to run for $5 \mathrm{~min}$, and then a $20 \mathrm{ml}$ sample was taken using vessels connected to detector through the pump.

For the determination of radon concentration in water samples, the following equation was used [21]:

$$
C_{\text {water }}=\frac{C_{\text {air }}\left(\frac{V_{\text {system }}-V_{\text {sample }}}{V_{\text {sample }}}-k\right)-C_{0}}{1000}
$$

where $C_{\text {water }}$ is radon concentration in water sample $\left(\mathrm{Bq} \cdot \mathrm{L}^{-1}\right), C_{\text {air }}$ is radon concentration in the measuring set-up after expelling the radon from the water indicated by AlphaGUARD (Bq m$\left.{ }^{-3}\right), C_{0}$ is the background radon concentration measured just before sampling for an empty set-up $\left(\mathrm{Bq} \cdot \mathrm{m}^{-3}\right), V_{\text {system }}$ is the interior volume of the measurement set-up $(\mathrm{ml}), V_{\text {sample }}$ is the volume of the water sample $(\mathrm{mL})$ and $k$ is the partition coefficient which depends on the temperature of the water sample.

The final result is calculated by taking into consideration the value of the diffusion coefficient, which depends on the temperature [21]:

$$
k=0.106+0.405 \mathrm{e}^{-0.052 T}
$$

where, $k$ is the diffusion coefficient of radon; $T$ is the temperature of water $\left[{ }^{\circ} \mathrm{C}\right]$.

\subsection{Determination of Equilibrium Factor}

The equilibrium factors between radon its decay is defined by [22]:

$$
F=\frac{0.105 \cdot C_{1}+0.516 \cdot C_{2}+0.379 \cdot C_{3}}{C_{0}}
$$

where $C_{j}$ is the concentrations of $f^{\text {th }}$ radon decay in the house (Bq. $\left.\mathrm{m}^{-3}\right)$, respectively ( $j=1,2$ and 3 for ${ }^{218} \mathrm{Po},{ }^{214} \mathrm{~Pb}$ and ${ }^{214} \mathrm{Bi}$ ), $C_{0}$ is the radon concentration in $\operatorname{room}\left(\mathrm{Bq} \cdot \mathrm{m}^{-3}\right)$.

\subsection{Determination of Annual Committed Equivalent Doses Due to the Inhalation of Radon Decay Products in the Respiratory Tract of an Adult Member of the Public in the Shower}

According to the ICRP Publication 66 [22] [23] (Figure 3), the human respiratory tract is divided into two major regions: the thoracic $\mathrm{TH}$ and extrathoracic ET regions. The thoracic region is divided into four sub-regions (alveolar interstitium $\mathrm{AI}$, bronchioles bb, bronchi $\mathrm{BB}$ and lymphatics $\mathrm{LN}_{\mathrm{TH}}$ ), and the extrathoracic 


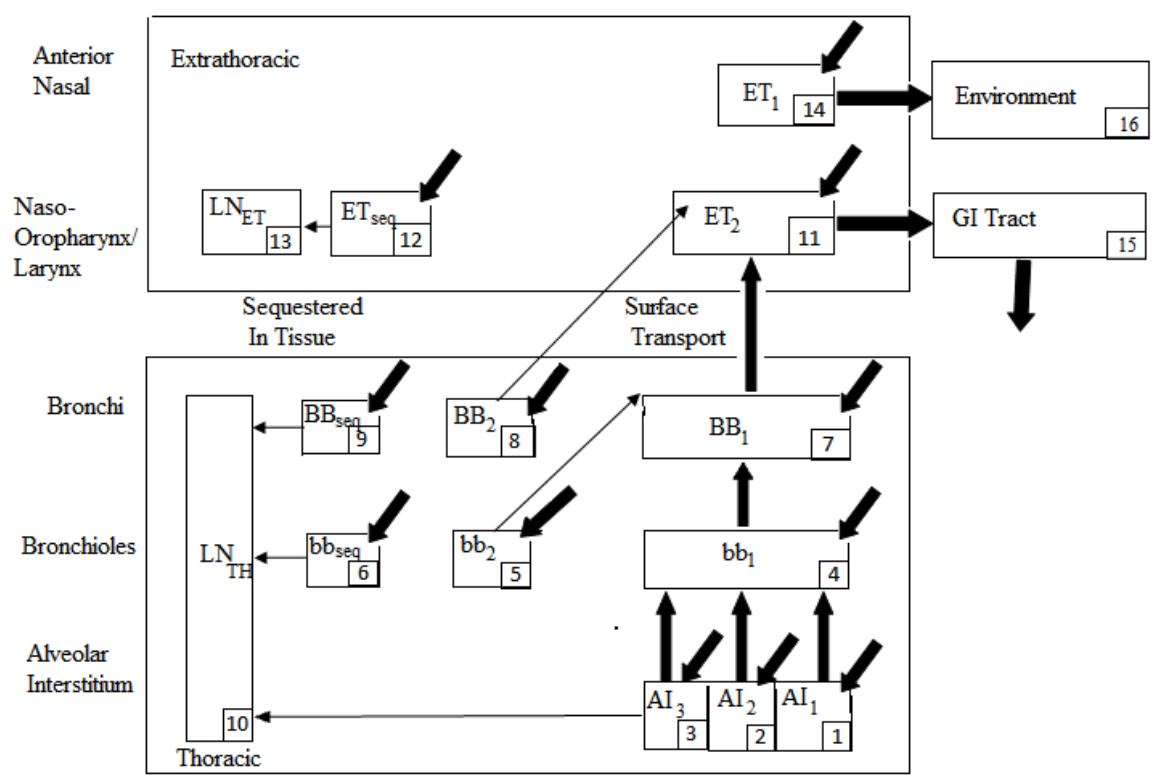

Figure 3. Compartment model showing particle transport from each region.

region is divided into three sub-regions (anterior nasal ET1, posterior nasal passage, larynx, pharynx and mouth $\mathrm{ET}_{2}$ and lymphatics $\mathrm{LN}_{\mathrm{ET}}$ ). There are ten compartments in the thoracic region of the human respiratory tract numbered from 1 to 10 and, respectively, named $\mathrm{AI}_{1}, \mathrm{AI}_{2}, \mathrm{AI}_{3}, \mathrm{bb}_{1}, \mathrm{bb}_{2}, \mathrm{bb}_{\text {seq, }}, \mathrm{BB}_{1}, \mathrm{BB}_{2}, \mathrm{BB}_{\text {seq }}$ and $\mathrm{LN}_{\mathrm{TH}}$. The extrathoracic region contains four compartments numbered from 11 to 14 and, respectively named $\mathrm{ET}_{2}, \mathrm{ET}_{\text {seq, }}, \mathrm{LN}_{\mathrm{ET}}$ and $\mathrm{ET}_{1}$. The thin arrows on Figure 3 given by the Biokinetic Model of Respiratory Tract denote the mechanical clearance of particles (numerical values shown are the fractional rate per day).

Inhaled radon decay-product radionuclides are assumed to be attached to particles of an activity median aerodynamic diameter of $200 \mathrm{~nm}$. The rate of change of a $f^{\text {th }}$ radon decay product alpha-activity in a compartment $i$ of the respiratory tract at any time is given by the following [23]:

$$
\frac{\mathrm{d} A_{c}^{i}(j)}{\mathrm{d} t}=F_{d}(i) I_{0}(j)+\sum_{n} \lambda_{n, i} A_{c}^{n}(j)-\left(\sum_{n} \lambda_{i, n}+\lambda_{j}\right) A_{c}^{i}(j)
$$

where $F_{d}(i)$ is the fractional deposition in the compartment $i$ of the respiratory tract of different members of the public (ICRP), $I_{0}(j)=B \cdot C(j)$; where $B$ is the average breathing rate $\left(1.2 \mathrm{~m}^{3} \cdot \mathrm{h}^{-1}\right)$ for the members of the public. $C(j)$ $\left(\mathrm{Bq} \cdot \mathrm{m}^{-3}\right)$ is the concentration of the $f^{\text {th }}$ radon decay product in the shower air, $\lambda_{n, i}=m_{n, i}+S_{s}$; where $m_{n, i}$ is the clearance rate from region $n$ to region $i$ due to particle transport and $S_{s}$ is the clearance rate due to particle absorption into blood (ICRP). The absorption rate of material into blood is the same in all regions of the respiratory tract, except in the anterior nasal passages $\left(\mathrm{ET}_{1}\right)$, where no absorption occurs [23]. $\lambda_{i, n}=m_{i, n}+S_{s}$; where $m_{i, n}$ is the clearance rate from regions $i$ to $n$ due to particle transport and $\lambda_{j}$ is the radioactive constant of the $f^{\text {th }}$ radon decay product. 
Alpha-activities corresponding to the th ${ }^{\text {th }}$ radond ecay product in each of the 14 compartments of the respiratory tract as functions of time are obtained by solving Equation (8).

The equivalent dose in the tissue $T$ of the respiratory tract for a radon decay product $f^{\text {th }}$ is given by the following:

$$
H_{T}(j)=\int_{0}^{t_{e}^{\prime}} \dot{H}_{T}(j)(t) \mathrm{d} t
$$

where $t_{e}^{\prime}$ is the exposure time of the tissue $T$ and $\dot{H}_{T}(j)$ is the alpha-equivalent dose rate $\left(\mathrm{Sv} \cdot \mathrm{s}^{-1}\right)$ in a tissue $T$ of the respiratory tract of an individual due to the inhalation of the $f^{\text {th }}$ radon decay given by:

$$
\dot{H}_{T}(j)(t)=A_{c}^{T}(j)(t) \cdot Q \cdot k \cdot \frac{K_{j} R_{j} S_{j}}{m_{T}}
$$

where $A^{T}(j)(t)(\mathrm{Bq})$ is the alpha-activity of the $f^{\text {th }}$ radon decay product in the tissue $T$ of the respiratory tract, $Q$ is the quality factor, which is equal to 20 for $\alpha$-particles (ICRP-66, 1994). $m_{T}$ is the mass of the target tissue $T, K_{j}$ is the branching ratio, $R_{j}$ is the range of the $\alpha$-particle emitted by the $f^{\text {th }}$ radon decay product, $S_{j}$ is the stopping power of the tissue $T$ for the emitted $\alpha$-particle and k $\left(1.6 \times 10^{-10}\right)$ is a conversion factor. $R_{j}$ and $S_{j}$ were calculated by using the SRIM program using the elemental chemical composition of tissues given in the ICRP publication 66 [23].

Regional doses, weighted with factors assigned for the partition of radiation detriment, are summed to give a value of committed equivalent dose for the thoracic $H_{T H}(j)$ and extrathoracic $H_{E T}(j)$ regions. According to the ICRP 66 [23], we have the following equations:

$$
H_{T H}(j)=A_{B B} H_{B B}(j)+A_{b b} H_{b b}(j)+A_{A I} H_{A I}(j)
$$

and

$$
H_{E T}(j)=A_{E T 1} H_{E T 1}(j)+A_{E T 2} H_{E T 2}(j)
$$

where $H_{B B}(j), H_{b b}(j)$ and $H_{A I}(j)$ are the equivalent doses in the $\mathrm{BB}, \mathrm{bb}$ and $\mathrm{AI}$ tissues of the thoracic region, respectively; $H_{E T 1}(j)$ and $H_{E T 2}(j)$ are the equivalent doses in the $\mathrm{ET}_{1}$ and $\mathrm{ET}_{2}$ tissues of the extrathoracic region, respectively; $A_{B B}=0.333, A_{b b}=0.333$ and $A_{A I}=0.333$ are the weighting factors for the partition of radiation detriment for the $\mathrm{BB}, \mathrm{bb}$ and $\mathrm{AI}$ tissues of the thoracic region, respectively, and $A_{E T 1}=0.001$ and $A_{E T 2}=1$ are the weighting factors for the partition of radiation detriment for the $\mathrm{ET}_{1}$ and $\mathrm{ET}_{2}$ extrathoracic regions [23].

The annual effective dose (mSv $\cdot \mathrm{y}^{-1} \cdot \mathrm{h}^{-1}$ exposure) due to short-lived radon decay products to the in the shower air was evaluated by using the following equation:

$$
E=0.12\left[H_{T H}\left({ }^{218} \mathrm{Po}\right)+H_{T H}\left({ }^{214} \mathrm{Po}\right)\right]+0.025\left[H_{E T}\left({ }^{218} \mathrm{Po}\right)+H_{E T}\left({ }^{214} \mathrm{Po}\right)\right]
$$

The annual effective dose $\left(\mathrm{mSv} \cdot \mathrm{y}^{-1} \cdot \mathrm{h}^{-1}\right.$ of exposure) due to the radon decay to the members of the public was also estimated according to the following formula 
[24]:

$$
E=A_{c}\left({ }^{222} \mathrm{Rn}\right) \times F \times t \times D
$$

where $A_{c}\left({ }^{222} \mathrm{Rn}\right)$ is the radon concentration in the shower air $\left(\mathrm{Bq} \cdot \mathrm{m}^{-3}\right), F$ is the equilibrium factor between radon and its decay in the shower air, $t=1 \mathrm{~h} \cdot \mathrm{y}^{-1}$ and $D=9.0 \times 10^{-6} \mathrm{mSv}\left(\mathrm{Bq} \cdot \mathrm{m}^{-3} \cdot \mathrm{h}\right)^{-1}$ is the dose conversion factor.

\section{Results and Discussion}

\subsection{Radon Distribution}

The results of measurements of radon concentration in water samples are presented in Table 2. The radon concentration in the water samples varied from $10.47 \mathrm{~Bq} \cdot \mathrm{L}^{-1}$ to $11.80 \mathrm{~Bq} \cdot \mathrm{L}^{-1}$, with an average value of $10.61 \mathrm{~Bq} \cdot \mathrm{L}^{-1}$. This value of radon concentration in water is used the key input for simulation; the CFD model was developed for radon dispersion study in shower model.

In order to investigate the spatial and temporal distribution of radon concentrations as well as its decay using CFD model, contours of radon concentrations at the symmetrical plane $(y=1.5 \mathrm{~m})$ has been plotted and shown in Figure 4. During early times, it can be seen that the radon concentrations high near shower heads, with the passage of time the radon concentrations dispersed into the shower environment. The distribution of radon concentrations reached steady state from $30 \mathrm{~min}$. Also, we notice that the distribution of ${ }^{218} \mathrm{Po}$ and ${ }^{214} \mathrm{~Pb}$ is similar to that of ${ }^{222} \mathrm{Rn}$, and this was also found in other studies [20].

Table 3 illustrates the ingrowths of the radon decay products by following the equilibrium factor (F). The equilibrium factor is defined as the ratio of the equilibrium equivalent radon concentration and of the radon concentration. By

Table 2. Radon concentration in water in various zones of Beni-Mellal.

\begin{tabular}{cc}
\hline Water sample & $A_{c}\left({ }^{222} \mathrm{Rn}\right)\left(\mathrm{Bq} \cdot \mathrm{L}^{-1}\right)$ \\
\hline BM1 & 10.54 \\
BM2 & 10.47 \\
BM3 & 10.61 \\
BM4 & 10.84 \\
\hline
\end{tabular}

Table 3. Average radon concentration $\left(\mathrm{Bq} \cdot \mathrm{m}^{-3}\right)$ for various times.

\begin{tabular}{ccccccc}
\hline Time $(\mathrm{min})$ & $\boldsymbol{A}_{\boldsymbol{c}}\left({ }^{222} \mathrm{Rn}\right)$ & $\boldsymbol{A}_{c}\left({ }^{218} \mathrm{Po}\right)$ & $\boldsymbol{A}_{\boldsymbol{c}}\left({ }^{214} \mathrm{~Pb}\right)$ & $\boldsymbol{A}_{c}\left({ }^{214} \mathrm{Bi}\right)$ & $\boldsymbol{A}_{c}\left({ }^{214} \mathrm{Po}\right)$ & $F$ \\
\hline 5 & 249.35 & 163.48 & 92.84 & 81.35 & 81.35 & 0.38 \\
10 & 417.27 & 287.18 & 172.88 & 151.96 & 151.96 & 0.42 \\
20 & 604.54 & 432.19 & 271.72 & 239.32 & 239.32 & 0.45 \\
30 & 701.18 & 516.85 & 336.06 & 296.40 & 296.40 & 0.48 \\
35 & 713.91 & 539.64 & 360.45 & 318.22 & 318.22 & 0.50 \\
40 & 714.8 & 555.96 & 382.54 & 338.05 & 338.05 & 0.53 \\
\hline
\end{tabular}


Time
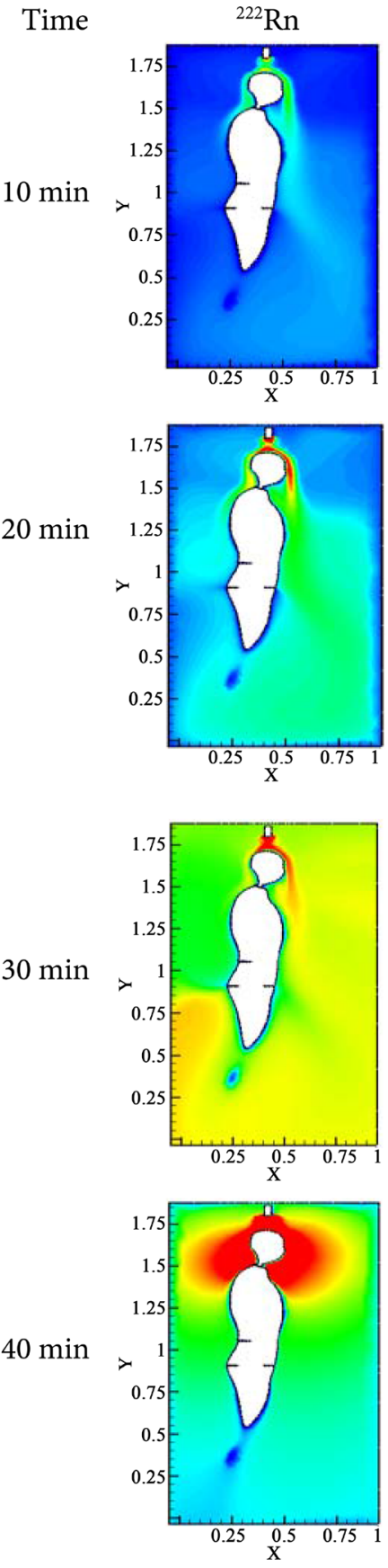

$\begin{array}{llllllllll}1.26 & 94.23 & 187.21 & 280.18 & 378.15 & 466.13 & 559.10 & 652.07 & 745.04 & 838.02\end{array}$
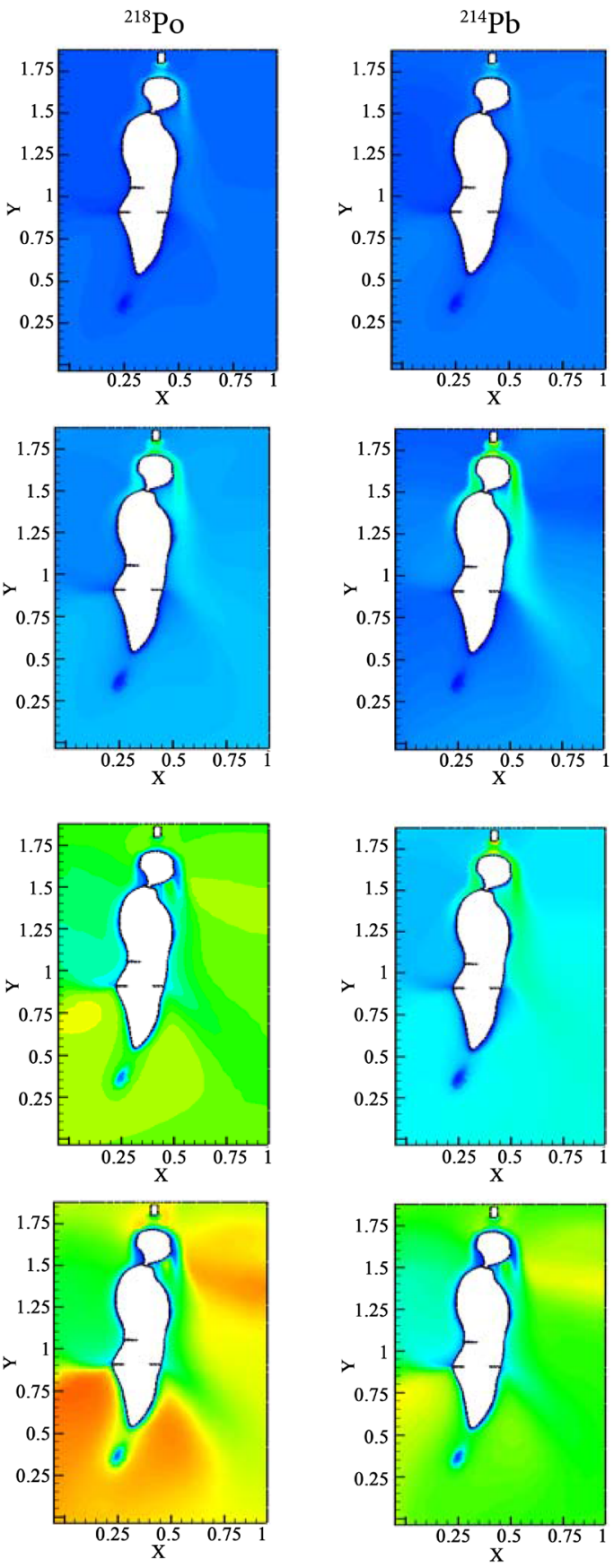

Figure 4. Contours of radon concentration and its decay $\left(\mathrm{Bq} \cdot \mathrm{m}^{-3}\right)$ at various times, in the studied shower at plane $(Z=0.5 \mathrm{~m})$.

increasing the time a significant increase of the equilibrium factor was observed between radon and its decay. The increase of the equilibrium factor can be due also to radon decay products becoming attached to tiny water drops suspended in the air. This fact is in agreement with the earlier work of Chu and Liu [25]. 


\subsection{The Effect of Temperature on Radon Dispersion}

Five cases have been considered in order to investigate the effects of temperature changes on radon concentration and its decay inside the shower. The temperature values are $20^{\circ} \mathrm{C}, 25^{\circ} \mathrm{C}, 30^{\circ} \mathrm{C}, 35^{\circ} \mathrm{C}$ and $40^{\circ} \mathrm{C}$. In these cases, the relative humidity has been fixed at $60 \%$. Contours of radon distribution and its decay at different temperatures are illustrated in Figure 5. From the figure, it is also clear that the radon concentration at the centre of the shower to that in the vicinity of the source (i.e. shower head), decreases with an increase in temperature. This may be due to the fact that, the radon is soluble in water, and its solubility decreases rapidly with temperature. Increasing the temperature has the same effect on the decay products as it does for the ${ }^{222} \mathrm{Rn}$. The average values of radon concentration and its decay in this case are summarized in Table 4. It is seen from this table that the equilibrium factor increase when the temperature increase. Then this increase will result in a larger decay product attachment rate.

$\mathrm{T}\left({ }^{\circ} \mathrm{C}\right)$ 25
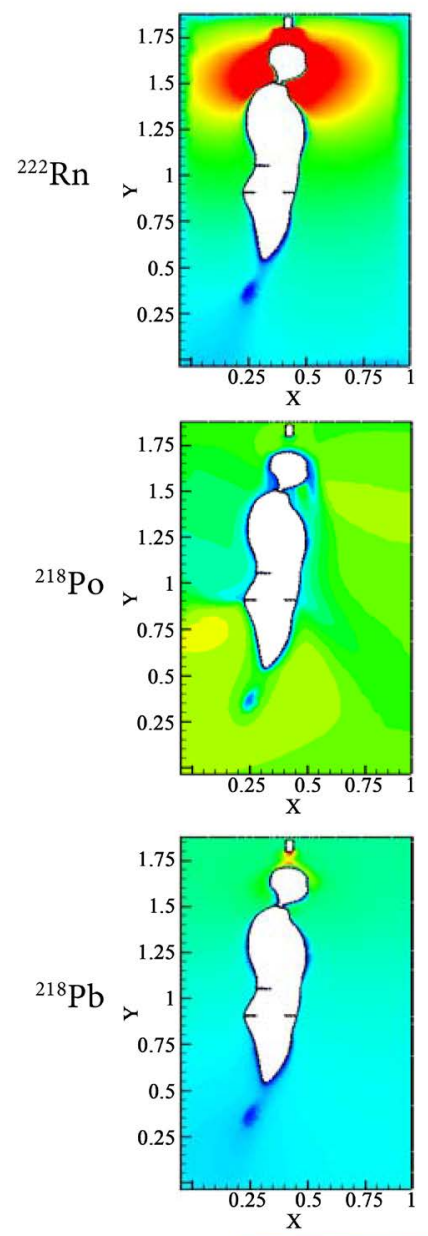

$\begin{array}{llllllllll}1.26 & 94.23 & 187.21 & 280.18 & 378.15 & 466.13 & 559.10 & 652.07 & 745.04 & 838.02\end{array}$
35
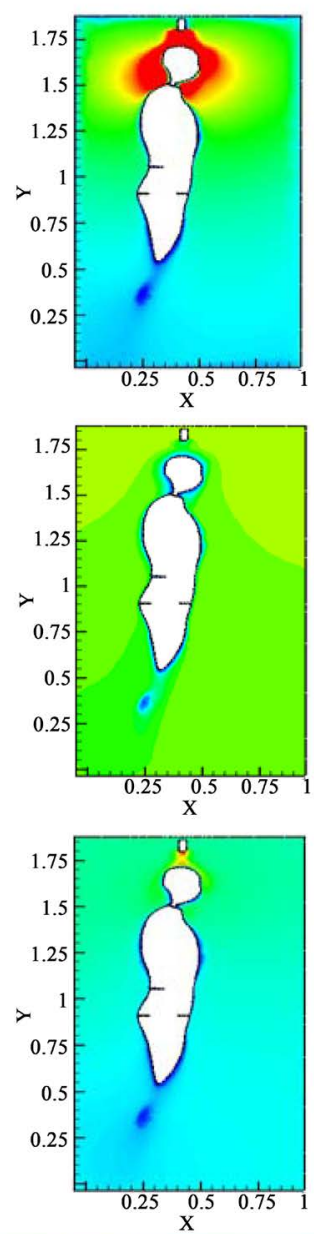
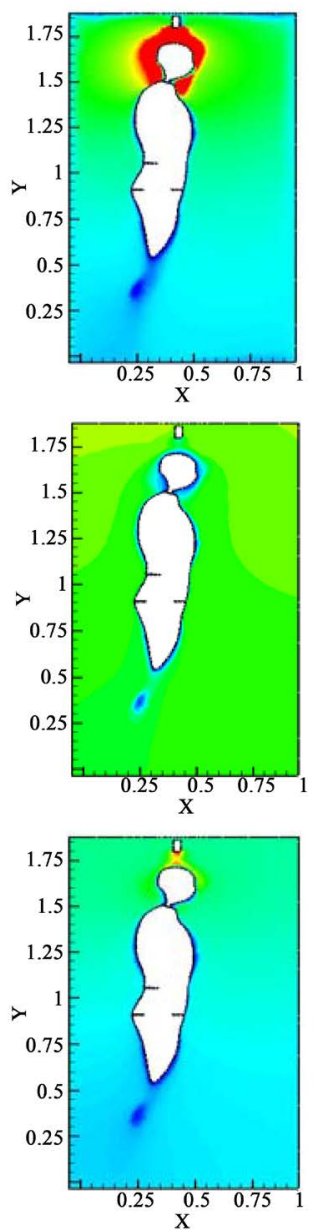
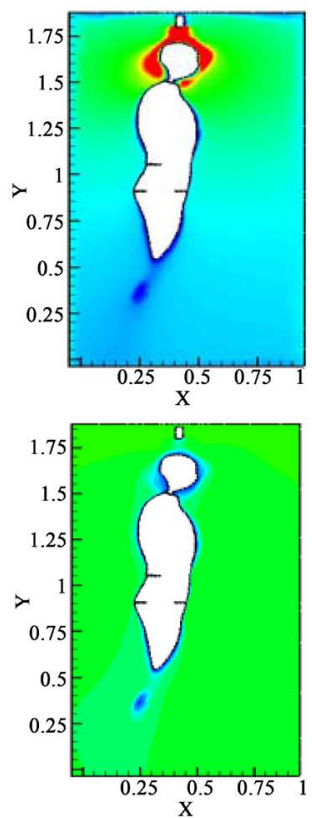

40

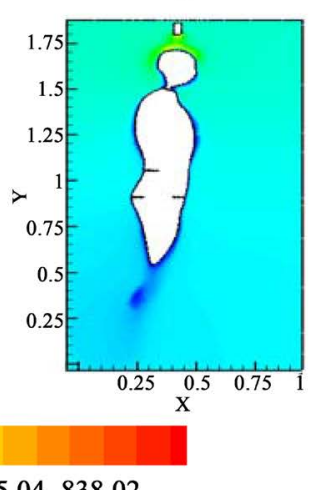

Figure 5. Contours of radon concentration and its decay $\left(\mathrm{Bq} \cdot \mathrm{m}^{-3}\right)$ as a function of temperature, in the studied shower at plane $(\mathrm{Z}=0.5 \mathrm{~m})$. 


\subsection{The Effect of Relative Humidity on Radon Dispersion}

In order to investigate the effect of relative humidity on the radon concentration and its decay in the shower, the relative humidity was set at: $50 \%, 60 \%, 70 \%$, $80 \%$ and $90 \%$. In these cases, the temperature is set at $20^{\circ} \mathrm{C}$. The results of the simulation are shown in Table 5. It is seen from this table that the radon decay activity grows with relative humidity, while the radon level is constant. The higher the relative humidity, the higher the aerosol particle concentration, therefore, the higher is the radioactive equilibrium factor and the process of attachment becomes faster than the deposition of unattached particles on the surface [26].

Contours of radon distribution and its decay are plotted in Figure 6 for different value of relative humidity, it can be seen that there is no increase of the radon concentration of this case. However, the maximum value of the ${ }^{218} \mathrm{Po}$ and ${ }^{214} \mathrm{~Pb}$ concentration in the shower is increasing with increasing relative humidity.

\subsection{Committed Equivalent Doses Due to Radon Short-Lived Alpha-Emitting Decay Products in the Respiratory Tract of Members of the Public}

Annual committed equivalent doses per hour of exposure due to the ${ }^{218} \mathrm{Po}\left(\mathrm{H}_{\mathrm{T}}\right.$ $\left.\left.{ }^{(218} \mathrm{Po}\right)\right)$ and ${ }^{214} \mathrm{Po}\left(\mathrm{H}_{\mathrm{T}}\left({ }^{214} \mathrm{Po}\right)\right)$ have been evaluated in the respiratory tract of different age groups of the members of the general public from the inhalation of air inside the shower. Data obtained for the adult males and females are shown in

Table 4. Average radon concentration $\left(\mathrm{Bq} \cdot \mathrm{m}^{-3}\right)$ for various temperatures with $V=0.2$ $\mathrm{L} \cdot \mathrm{S}^{-1}$.

\begin{tabular}{ccccccc}
\hline $\begin{array}{c}\text { Temperatures } \\
\text { of water }\left({ }^{\circ} \mathrm{C}\right)\end{array}$ & $A_{c}\left({ }^{222} \mathrm{Rn}\right)$ & $A_{c}\left({ }^{218} \mathrm{Po}\right)$ & $A_{c}\left({ }^{214} \mathrm{~Pb}\right)$ & $A_{c}\left({ }^{214} \mathrm{Bi}\right)$ & $A_{c}\left({ }^{214} \mathrm{Po}\right)$ & $F$ \\
\hline 20 & 897.67 & 653.63 & 419.72 & 370.00 & 370.00 & 0.47 \\
25 & 714.84 & 544.51 & 367.10 & 324.19 & 324.19 & 0.51 \\
30 & 709.15 & 541.45 & 359.24 & 335.13 & 335.13 & 0.53 \\
35 & 688.76 & 535.12 & 348.38 & 325.81 & 325.81 & 0.54 \\
40 & 418.59 & 335.95 & 238.95 & 211.03 & 211.03 & 0.56 \\
\hline
\end{tabular}

Table 5. Average radon concentration $\left(\mathrm{Bq} \cdot \mathrm{m}^{-3}\right)$ for various relative humidity with $T=$ $20^{\circ} \mathrm{C}$.

\begin{tabular}{ccccccc}
\hline $\mathrm{RH}(\%)$ & $A_{c}\left({ }^{222} \mathrm{Rn}\right)$ & $A_{c}\left({ }^{218} \mathrm{Po}\right)$ & $A_{c}\left({ }^{214} \mathrm{~Pb}\right)$ & $A_{c}\left({ }^{214} \mathrm{Bi}\right)$ & $A_{c}\left({ }^{214} \mathrm{Po}\right)$ & $F$ \\
\hline 40 & 714.84 & 491.98 & 296.17 & 260.33 & 260.33 & 0.42 \\
50 & 714.84 & 512.76 & 323.58 & 285.04 & 285.04 & 0.46 \\
60 & 714.84 & 520.89 & 334.48 & 294.86 & 294.86 & 0.47 \\
70 & 714.84 & 545.15 & 367.53 & 324.57 & 324.57 & 0.51 \\
80 & 714.84 & 589.99 & 430.66 & 381.17 & 381.17 & 0.59 \\
90 & 714.84 & 620.77 & 475.43 & 421.17 & 421.17 & 0.65 \\
\hline
\end{tabular}



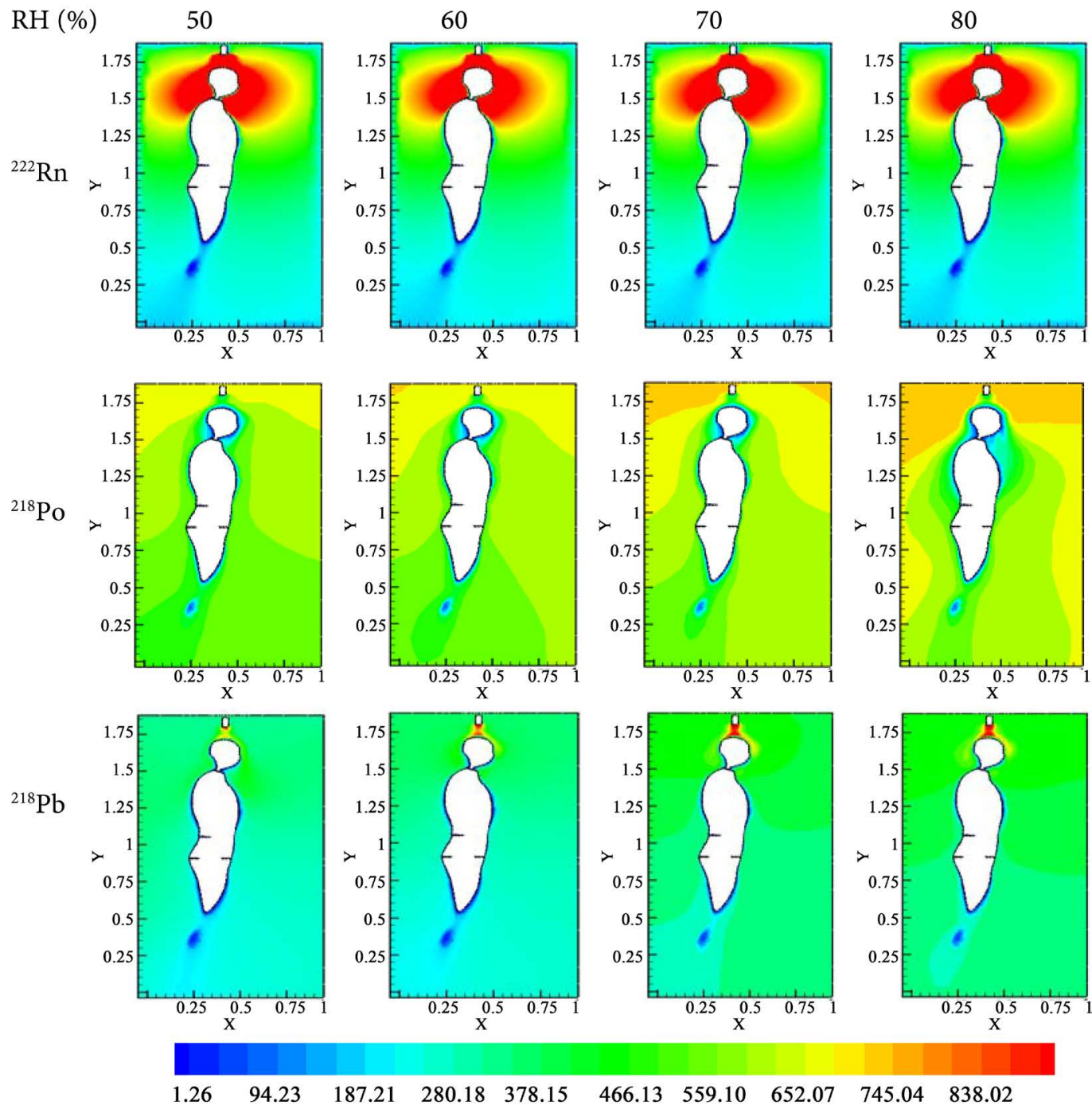

Figure 6. Contours of radon concentration and its decay $\left(\mathrm{Bq} \cdot \mathrm{m}^{-3}\right)$ as a function of relative humidity, in the studied shower at plane $(\mathrm{Z}=0.5 \mathrm{~m})$.

Table 6 and Table 7. In these tables we can observe that the annual committed equivalent doses due to the ${ }^{214} \mathrm{Po}$ are smaller than those due to ${ }^{218} \mathrm{Po}$ in both the ET and TH regions. This is due to the fact that ${ }^{214} \mathrm{Po}$ has a very short half-life $\left(1.64 \times 10^{-4} \mathrm{~s}\right)$ compared with the exposure time of the tissues: this means that ${ }^{214} \mathrm{Po}$ comes essentially from the disintegration of ${ }^{218} \mathrm{Po}$ present in the ET and $\mathrm{TH}$ regions. The results also showed that the equivalent dose the annual committed equivalent dose due to ${ }^{218} \mathrm{Po}$ is higher in the ET region than in the $\mathrm{TH}$ region with a factor of 100 (Table 6). Then, the extrathoracic region is more exposed in the respiratory tract.

Annual effective doses due to radon decay from the inhalation of air inside the shower by the members of the general public were evaluated by using the model given here (Equation (13)) and the UNSCEAR formula (Equation (14)) (Table 8). Data obtained for the average effective dose obtained by using the model given here for different age groups of individuals in the shower were found in 
Table 6. Data obtained for annual committed equivalent dose (in Sv $\cdot \mathrm{y}^{-1} \cdot \mathrm{h}^{-1}$ exposure) due to ${ }^{218} \mathrm{Po}$ and ${ }^{214} \mathrm{Po}$ in the compartments of the respiratory tract for adult male from the inhalation of air in the shower.

\begin{tabular}{|c|c|c|c|c|c|c|c|c|c|c|}
\hline \multirow{3}{*}{$\begin{array}{l}\text { Time } \\
(\min )\end{array}$} & \multicolumn{5}{|c|}{${ }^{218} \mathrm{Po}$} & \multicolumn{5}{|c|}{${ }^{214} \mathrm{Po}$} \\
\hline & \multicolumn{3}{|c|}{ Thoracic region } & \multicolumn{2}{|c|}{ Exthrathoracic region } & \multicolumn{3}{|c|}{ Thoracic region } & \multicolumn{2}{|c|}{ Exthrathoracic region } \\
\hline & AI & bb & BB & $\mathrm{ET}_{1}$ & $\mathbf{E T}_{2}$ & AI & bb & BB & $\mathrm{ET}_{1}$ & $\mathrm{ET}_{2}$ \\
\hline 10 & $1.84 \times 10^{-8}$ & $2.62 \times 10^{-6}$ & $7.61 \times 10^{-6}$ & $8.39 \times 10^{-7}$ & $3.14 \times 10^{-5}$ & $5.24 \times 10^{-15}$ & $7.74 \times 10^{-13}$ & $2.09 \times 10^{-13}$ & $2.36 \times 10^{-13}$ & $1.14 \times 10^{-11}$ \\
\hline 20 & $2.73 \times 10^{-8}$ & $3.90 \times 10^{-6}$ & $1.13 \times 10^{-6}$ & $1.24 \times 10^{-6}$ & $4.68 \times 10^{-5}$ & $7.80 \times 10^{-15}$ & $1.15 \times 10^{-12}$ & $3.12 \times 10^{-13}$ & $3.51 \times 10^{-13}$ & $1.69 \times 10^{-11}$ \\
\hline 30 & $3.09 \times 10^{-8}$ & $4.40 \times 10^{-6}$ & $1.2710^{-6}$ & $1.41 \times 10^{-6}$ & $5.29 \times 10^{-5}$ & $8.81 \times 10^{-15}$ & $1.30 \times 10^{-12}$ & $3.52 \times 10^{-13}$ & $3.96 \times 10^{-13}$ & $1.91 \times 10^{-11}$ \\
\hline 40 & $3.15 \times 10^{-8}$ & $4.49 \times 10^{-6}$ & $1.3010^{-6}$ & $1.43 \times 10^{-6}$ & $5.39 \times 10^{-5}$ & $8.99 \times 10^{-15}$ & $1.32 \times 10^{-12}$ & $3.59 \times 10^{-13}$ & $4.04 \times 10^{-13}$ & $1.95 \times 10^{-11}$ \\
\hline
\end{tabular}

Table 7. Data obtained for annual committed equivalent dose (in Sv $\cdot \mathrm{y}^{-1} \cdot \mathrm{h}^{-1}$ exposure) due to ${ }^{218} \mathrm{Po}$ and ${ }^{214} \mathrm{Po}$ in the compartments of the respiratory tract for adult female from the inhalation of air in the shower.

\begin{tabular}{|c|c|c|c|c|c|c|c|c|c|c|}
\hline \multirow{3}{*}{ Time (min) } & \multicolumn{5}{|c|}{${ }^{218} \mathrm{Po}$} & \multicolumn{5}{|c|}{${ }^{214} \mathrm{Po}$} \\
\hline & \multicolumn{3}{|c|}{ Thoracic region } & \multicolumn{2}{|c|}{ Exthrathoracic region } & \multicolumn{3}{|c|}{ Thoracic region } & \multicolumn{2}{|c|}{ Exthrathoracic region } \\
\hline & AI & bb & BB & $\mathrm{ET}_{1}$ & $\mathrm{ET}_{2}$ & AI & $\mathrm{bb}$ & BB & $\mathrm{ET}_{1}$ & $\mathrm{ET}_{2}$ \\
\hline 10 & $1.31 \times 10^{-8}$ & $2.23 \times 10^{-6}$ & $7.08 \times 10^{-7}$ & $6.82 \times 10^{-7}$ & $2.49 \times 10^{-5}$ & $3.80 \times 10^{-15}$ & $6.29 \times 10^{-13}$ & $1.83 \times 10^{-13}$ & $1.96 \times 10^{-13}$ & $9.05 \times 10^{-12}$ \\
\hline 20 & $1.95 \times 10^{-8}$ & $3.31 \times 10^{-6}$ & $1.05 \times 10^{-6}$ & $1.01 \times 10^{-6}$ & $3.70 \times 10^{-5}$ & $5.65 \times 10^{-15}$ & $9.36 \times 10^{-13}$ & $2.73 \times 10^{-13}$ & $2.92 \times 10^{-13}$ & $1.34 \times 10^{-11}$ \\
\hline 30 & $2.20 \times 10^{-8}$ & $3.74 \times 10^{-6}$ & $1.19 \times 10^{-6}$ & $1.14 \times 10^{-6}$ & $4.18 \times 10^{-5}$ & $6.39 \times 10^{-15}$ & $1.05 \times 10^{-12}$ & $3.08 \times 10^{-13}$ & $3.30 \times 10^{-13}$ & $1.52 \times 10^{-11}$ \\
\hline 40 & $2.24 \times 10^{-8}$ & $3.82 \times 10^{-6}$ & $1.21 \times 10^{-6}$ & $1.16 \times 10^{-6}$ & $4.27 \times 10^{-5}$ & $6.51 \times 10^{-15}$ & $1.07 \times 10^{-13}$ & $3.14 \times 10^{-13}$ & $3.37 \times 10^{-13}$ & $1.55 \times 10^{-11}$ \\
\hline
\end{tabular}

Table 8. Data obtained for the effective dose (in Sv $\cdot \mathrm{y}^{-1} \cdot \mathrm{h}^{-1}$ of exposure) due to the short-lived radon decay products from the inhalation of air in the shower by different age groups by using the method here and the UNSCEAR (2000) dose conversion coefficient.

\begin{tabular}{|c|c|c|c|c|c|c|}
\hline \multirow{3}{*}{$\begin{array}{l}\text { Time } \\
(\min )\end{array}$} & \multicolumn{6}{|c|}{ Effective dose (Sv. $\mathrm{y}^{-1} \cdot \mathrm{h}^{-1}$ of exposure) } \\
\hline & \multicolumn{5}{|c|}{ This method } & \multirow{2}{*}{ UNSCEAR } \\
\hline & H-adult & F-adulte & Child $10 \mathrm{y}$ & Child $5 \mathrm{y}$ & Average & \\
\hline 10 & $1.18 \times 10^{-6}$ & $1.04 \times 10^{-6}$ & $1.57 \times 10^{-6}$ & $2.36 \times 10^{-6}$ & $1.54 \times 10^{-6}$ & $1.50 \times 10^{-6}$ \\
\hline 20 & $1.75 \times 10^{-6}$ & $1.56 \times 10^{-6}$ & $2.34 \times 10^{-6}$ & $3.51 \times 10^{-6}$ & $2.29 \times 10^{-6}$ & $2.23 \times 10^{-6}$ \\
\hline 30 & $1.98 \times 10^{-6}$ & $1.76 \times 10^{-6}$ & $2.64 \times 10^{-6}$ & $3.96 \times 10^{-6}$ & $2.59 \times 10^{-6}$ & $2.52 \times 10^{-6}$ \\
\hline 40 & $2.02 \times 10^{-6}$ & $1.79 \times 10^{-6}$ & $2.69 \times 10^{-6}$ & $4.04 \times 10^{-6}$ & $2.64 \times 10^{-6}$ & $2.57 \times 10^{-6}$ \\
\hline
\end{tabular}

good agreement with those obtained by using the UNSCEAR model for the general public.

\section{Conclusion}

It has been shown in this study that by using CFD modeling one can determine the distribution of radon and its decay inside the air of the shower. The overall results show that the concentrations of radon and its progenies increase when a shower starts as well as when the temperature of water decreases. Annual committed equivalent doses due to ${ }^{218} \mathrm{Po}$ and ${ }^{214} \mathrm{Po}$ were determined in the respiratory tract of adult members of the public from the inhalation of air inside the 
shower. It has been shown that committed equivalent doses in the human respiratory tract depend on the human physiological condition (male or female). Owners must, therefore, use water with rationality and good ventilation of the shower to avoid any enhancement of exposure to radiation due to the inhalation of radon and its decay products.

\section{Conflicts of Interest}

The authors declare no conflicts of interest regarding the publication of this paper.

\section{References}

[1] Somlai, K., Tokonami, S., Ishikawa, T., Vancsura, P., Gáspár, M., Jobbágy, V., Somlai, J. and Kovács, T. (2007) ${ }^{222} \mathrm{Rn}$ Concentration of Water in the Balaton Highland and in the Southern Part of Hungary, and the Assessment of the Resulting Dose. Radiation Measurements, 42, 491-495. https://doi.org/10.1016/j.radmeas.2006.11.005

[2] Gruber, V., Maringer, F.J. and Landstetter, C. (2009) Radon and Other Natural Radionuclides in Drinking Water in Austria: Measurement and Assessment. Applied Radiation and Isotopes, 67, 913-917. https://doi.org/10.1016/j.apradiso.2009.01.056

[3] Khan, F., Ali, N., Khan, E.U., Khattak, N.U. and Khan, K. (2010) Radon Monitoring in Water Sources of Balakot and Mansehra Cities Lying on a Geological Fault Line. Radiation Protection Dosimetry, 138, 174-179. https://doi.org/10.1093/rpd/ncp214

[4] Prasad, Y., Prasad, G. and Ramola, R.C. (2009) Geohydrological Control on Radon Availability in Groundwater. Radiation Measurements, 44, 122-126. https://doi.org/10.1016/j.radmeas.2008.10.006

[5] Somlai, K., Tokonami, S., Ishikawa, T., Vancsura, P., Gaspar, M., Jobbagy, V., Somlai, J. and Kovacs, T. (2007) ${ }^{222} \mathrm{Rn}$ Concentration of Water in the Balaton Highland and in the Southern Part of Hungary, and the Assessment of the Resulting Dose. Radiation Measurements, 42, 491-495. https://doi.org/10.1016/j.radmeas.2006.11.005

[6] Ouabi, H. (2009) Modeling of Radon and Its Short-Lived Decay Products Emanating from Tap Water Used inside a House: Dose to Adult Members of the Public. Applied Radiation and Isotopes, 67, 115-121. https://doi.org/10.1016/j.apradiso.2008.07.010

[7] Kassi, B., Boukhair, A., Azkour, K., Fahad, M., Benjelloun, M. and Nourreddine, A.M. (2018) Assessment of Exposure Due to Technologically Enhanced Natural Radioactivity in Various Samples of Moroccan Building Materials. World Journal of Nuclear Science and Technology, 8, 176-189.

https://doi.org/10.4236/wjnst.2018.84015

[8] Augusto, L.L.X., Lopes, G.C. and Gonçalves, J.A.S. (2016) A CFD Study of Deposition of Pharmaceutical Aerosols under Different Respiratory Conditions. Brazilian Journal of Chemical Engineering, 33, 549-558. https://doi.org/10.1590/0104-6632.20160333s20150100

[9] Tong, Z., Zhong, W., Yu, A., Chan, H.K. and Yang, R. (2016) CFD-DEM Investigation of the Effect of Agglomerate-Agglomerate Collision on Dry Powder Aerosolisation. Journal of the Aerospace Sciences, 92, 109-121. https://doi.org/10.1016/j.jaerosci.2015.11.005

[10] Benjamin, A., Raj, S., Eusebius, G. and Ludovic, R. (2017) CFD Modeling of the 
Coke Combustion in an Industrial FCC Regenerator. Chemical Engineering Science, 170, 731-742. https://doi.org/10.1016/j.ces.2016.12.055

[11] Nasonova, A., Park, D.W., Charinpanitkul, T. and Kim, K.S. (2012) Numerical Analysis on Premixed Combustion of $\mathrm{H}_{2}-\mathrm{SiCl}_{4}$-Air System to Prepare $\mathrm{SiO}_{2}$ Particles. Journal of Industrial and Engineering Chemistry, 18, 509-512. https://doi.org/10.1016/j.jiec.2011.11.071

[12] Salem, A., Ahmad louiedarab, M. and Ghasemzadeh, K. (2011) CFD Approach for the Moisture Prediction in Spray Chamber for Drying of Salt Solution. Journal of Industrial and Engineering Chemistry, 17, 527-532. https://doi.org/10.1016/j.jiec.2010.10.023

[13] Chauhan, N., Chauhan, R.P., Joshi, M., Agarwal, T.K., Aggarwal, P. and Sahoo, B.K. (2014) Study of Indoor Radon Distribution Using Measurements and CFD Modeling. Journal of Environmental Radioactivity, 136, 105-111. https://doi.org/10.1016/j.jenvrad.2014.05.020

[14] Rabi, R. and Oufni, L. (2017) Study of Radon Dispersion in Typical Dwelling Using CFD Modeling Combined with Passive-Active Measurements. Radiation Physics and Chemistry, 139, 40-48. https://doi.org/10.1016/j.radphyschem.2017.04.012

[15] Urosevic, V., Nikezic, D. and Vulovic, S. (2008) A Theoretical Approach to Indoor Radon and Thoron Distribution. Journal of Environmental Radioactivity, 99, 1829-1833. https://doi.org/10.1016/j.jenvrad.2008.07.010

[16] de With, G. and de Jong, P. (2011) CFD Modelling of Thoron and Thoron Progeny in the Indoor Environment. Radiation Protection Dosimetry, 145, 1-7. https://doi.org/10.1093/rpd/ncr056

[17] Agarwal, T.K., Sahoo, B.K., Gaware, J.J., Joshi, M. and Sapra, B.K. (2014) CFD Based Simulation of Thoron $\left({ }^{220} \mathrm{Rn}\right)$ Concentration in a Delay Chamber for Mitigation Application. Journal of Environmental Radioactivity, 136, 16-21. https://doi.org/10.1016/j.jenvrad.2014.05.003

[18] Dieguez-Elizondo, P.M., Gil-Lopez, T., O’Donohoe, P.G., Navas, J.C. and Galvez-Huertac, M.A. (2017) An Analysis of the Radioactive Contamination Due to Radon in a Granite Processing Plant and Its Decontamination by Ventilation. Journal of Environmental Radioactivity, 167, 26-35. https://doi.org/10.1016/j.jenvrad.2016.11.016

[19] Akbari, K., Mahmoudi, J. and Ghanbari, M. (2013) Influence of Indoor Air Conditions on Radon Concentration in a Detached House. Journal of Environmental Radioactivity, 116, 166-173. https://doi.org/10.1016/j.jenvrad.2012.08.013

[20] Zhuo, W., Iida, T., Moriizumi, J., Aoyagi, T. and Takahashi, I. (2001) Simulation of the Concentrations and Distributions of Indoor Radon and Thoron. Radiation Protection Dosimetry, 93, 357-367. https://doi.org/10.1093/oxfordjournals.rpd.a006448

[21] Correa, J.N., Paschuk, S.A., Jaqueline, K. and Allan, F.N.P. (2014) Measurements of ${ }^{222} \mathrm{Rn}$ Activity in Well Water of the Curitiba Metropolitan Area (Brazil). Radiation Physics and Chemistry, 104, 108-111.

https://doi.org/10.1016/j.radphyschem.2014.01.006

[22] Rabi, R. and Oufni, L. (2018) Evaluation of Indoor Radon Equilibrium Factor Using CFD Modeling and Resulting Annual Effective Dose. Radiation Physics and Chemistry, 145, 213-221. https://doi.org/10.1016/j.radphyschem.2017.10.022

[23] ICRP (1994) Human Respiratory Tract Model for Radiological Protection. ICRP Publication 66. Annals of the ICRP, 24, 698-703.

https://doi.org/10.1016/0146-6453(94)90018-3

[24] United Nations Scientific Committee on the Effects of Atomic Radiation (UNSCEAR) 
(2000) Sources and Effects of Ionizing Radiation. United Nations, New York.

[25] Chu, T.C. and Liu, H.L. (1996) Simulated Equilibrium Factor Studies in Radon Chamber. Applied Radiation and Isotopes, 47, 543-550.

https://doi.org/10.1016/0969-8043(95)00334-7

[26] Swedjemark, G.A. (1983) The Equilibrium Factor. Health Physics, 45, 453-462. https://doi.org/10.1097/00004032-198308000-00021 